\title{
Challenges of Implementing Container Terminal Operating System: The Case of the Port of Mombasa from the Belt and Road Initiative (BRI) Perspective
}

Author(s): Victor Oyaro Gekara, Xuan-Vi Thanh Nguyen

Source: Journal of International Logistics and Trade 2020; 18(1):49-60

Published by: Jungseok Research Institute of International Logistics and Trade, Inha University

DOI: https://doi.org/10.24006/jilt.2020.18.1.049

The Journal of International Logistics and Trade is an official journal published by Jungseok Research Institute of International Logistics and Trade, Inha University, Korea. JILT welcomes manuscripts that advance the practice and science of logistics, trade, and other related fields.

Frequency: Quarterly (March, June, September, December)

Stable URL: https://www.ejilt.org

The Jungseok Research Institute of International Logistics and Trade is a specialized academic research institute representing Inha University and the Inha Foundation in Korea. The institute aims to become a representative institute in Northeast Asia in the research of logistics and trade.

Stable URL: https://jrieng.inha.ac.kr

(C) Copyright. Jungseok Research Institute of International Logistics and Trade.

This is an Open-Access article distributed under the terms of the Creative Commons Attribution NonCommercial License (http://creativecommons.org/licenses/by-nc/4.0/) which permits unrestricted noncommercial use, distribution, and reproduction in any medium, provided the original work is properly cited 


\title{
Challenges of Implementing Container Terminal Operating System: The Case of the Port of Mombasa from the Belt and Road Initiative (BRI) Perspective
}

\author{
Victor Oyaro Gekara ${ }^{1,}{ }^{*}$, Xuan-Vi Thanh Nguyen ${ }^{2}$ \\ ${ }^{1}$ College of Business, RMIT University, Melbourne, Australia \\ ${ }^{2}$ Department of Business, Quy Nhon University, Quy Nhon City, Vietnam
}

\begin{tabular}{ll} 
Received & March 02, 2020 \\
Revised & March 09, 2020 \\
Accepted & March 12, 2020 \\
& \multicolumn{1}{c}{ Gekara } \\
*Corresponding author: Victor Oyaro \\
\multicolumn{2}{c}{ College of Business, RMIT University, } \\
Melbourne, Australia \\
Tel: +61-9925550 \\
E-mail: victor.gekara@rmit.edu.au
\end{tabular}

\begin{abstract}
This paper examines the port of Mombasa's attempted implementation of computer-based terminal operating systems (TOS); the challenges faced and the outcomes. In addition to enhancing its operations efficiency, a key motivation for the technology was to facilitate better integration and connectivity to the Belt and Road as a key gateway along the key route. It utilised a qualitative single-case methodology, involving a combination of semi-structured interviews, non-participant observations and content analysis of relevant policy documents and reports provided by the port. The paper finds that the attempt to adopt and implement TOS at the port mostly failed as a result of a complex combination of technological, organisational and environmental factors. Most importantly, the wider business environment was ill equipped with the necessary information communication technology (ICT) infrastructure to support effective implementation. There was also a general lack of appropriately skilled workers to support and drive the same.
\end{abstract}

Keywords Container terminal operating systems, Mombasa port, Port technology, Maritime Silk Road, Belt and Road

\section{Introduction}

In the current highly competitive business environment, characterised by complex and fast-moving global supply chains, which demand logistics agility and just-in-time (JIT) production and distribution, advanced information communication technology (ICT) systems have become central and critical. Ports, and particularly container terminals, are the central nodes in these complex supply chains, so much so that their individual performance determines the performance of entire global supply chains. They are therefore under increasing innovative pressure to maintain optimum performance in terms of productivity and efficiency. Consequently, the past four decades, beginning in the mid-1980s, have seen a proliferation of ICT products specifically designed for the optimisation of container port administration, management and operations. These systems are generally known as Container Terminal Operating Systems or CTOS in abbreviation.

Particularly significant is that container terminal operations involve the concurrent exchange of vast amounts of documentation, data and information across a wide range of stakeholders, often vastly located internationally. Advanced ICT terminal management systems are therefore critical in any container terminal for efficient operations, customer satisfaction and competitiveness. The new ICT-CTOS promise such efficiency. Following the customer-centric view of the role of ports, as espoused by, for example Lee et al. (2018b), $21^{\text {st }}$ century port technologies, in addition to facilitating efficient internal operations coordination, serve the critical function of external customer and stakeholder process integration.

Against this background, this study examines how the port of Mombasa has, over the past few years, embarked on, operations capacity enhancement through the adoption of advanced ICT-TOS. As a key regional port on the East Coast of Africa and one that lies strategically on the Maritime Silk Road (Lee et al. 2018a), it is important for the port to enhance the efficiency of its internal operations but also, its ability to effectively integrate and effectively participate as a key gateway to the expansive and trade potential rich East and Central African region. The fact that the region comprises majority land-locked countries makes the role of the port, and the need for greater efficiencies, even more critical. Whilst a lot is said, both in academic and policy discussions, about the need for infrastructure and superstructure development for ports along the maritime silk road(MSR), not much has been examined regarding the need for and adoption of advanced ICT-based port operating systems. This is particularly 
so in the context of the African continent where little is known about technological enhancements in port operations. It is therefore crucial to think about the contextual challenges likely to make their adoption and implementation harder for ports in developing countries, especially in Africa and more especially, those that still retain a state land-lord administration model and continue to struggle with capital investment shortages, such as the port of Mombasa.

Thus, from a broader perspective, the paper contributes to growing and much needed knowledge on the challenges that undermine business digitalisation in developing economies (Ejiaku 2014; Lawrence and Tar 2010; Richardson 2011; Shih et al. 2008). In this respect, Datta (2011) calls for greater understanding of the "nuanced variety of conditions and contingencies that shape user adoption of e-commerce technologies" in developing countries. We present the argument of a complex convergence and interplay of a wide variety of factors, which may only be understaood through a comprehemsive and integrated analysis to appreciate the roles of government, industry and labour.

The paper is organised into seven sections. Following this introduction, Section two briefly outlines the MSR and the potential role of the port of Mombasa in facilitating greater regional logistics connectivity to the MSR. Section three presents a brief outline of container terminal operating systems (CTOS) followed by section four which describes the methods used in the study. Section five and six present data on the adoption and implementation of the system at the case port and the factors behind the challenges experienced and the outcomes observed. Section seven presents a brief duscussion of the findings while section eight concludes with consideration of implications, recommendations and suggetions for future research.

\section{Linterature review}

\subsection{Integration and connectivity to the Belt and Road Initiative (BRI)}

In the recent years since the introduction of the Belt and Road (BRI) initiative by China in 2013, there is a growing body of literature on the project and the topic generally (Georgiev 2015; Lee et al. 2018a, 2018b). Considering the global magnitude of the project and its potential to significantly reshape the current international trade and transportaton landscape, it is not surprising that it is attracting a lot of attention in both academic and policy debates. This is evident in the amount of research being conducted on it around the world but also the number of conferences, seminars and workshops dedicated to in the past few years (Lee et al. 2018b). Essentially, the Belt and Road project is a $21^{\text {st }}$ redefinition of the $19^{\text {th }}$ Century land-based Silk Road Economic Belt to include a maritime aspect - the $21^{\text {st }}$ Century Maritime Silk Road (Lee et al. 2018a). It was developed by the Chinese government in 2013 with the core aim of catalysing regional logistics infrastructure development and connnectivity within South-East Asia and to connect the region with Europe though South Asia and Africa (Cheng 2016; Du 2016). The core strategy, as noted by Lee et al. (2018b) is to cultivate economic clusters along the route organised around key ports, hinterland corridors and regional cities. On the African leg of the route, the trading clusters will be organised around the key ports of Kenya and Djibouti, as it proceeds through the Suez Canal towards Europe.

In this respect, the port of Mombasa occupies a key strategic location, which links the MSR to the expansive and resourcerich East and Central African hinterland through the Northern Corridor (Figure 1) and potentially the Central corridor (Figure

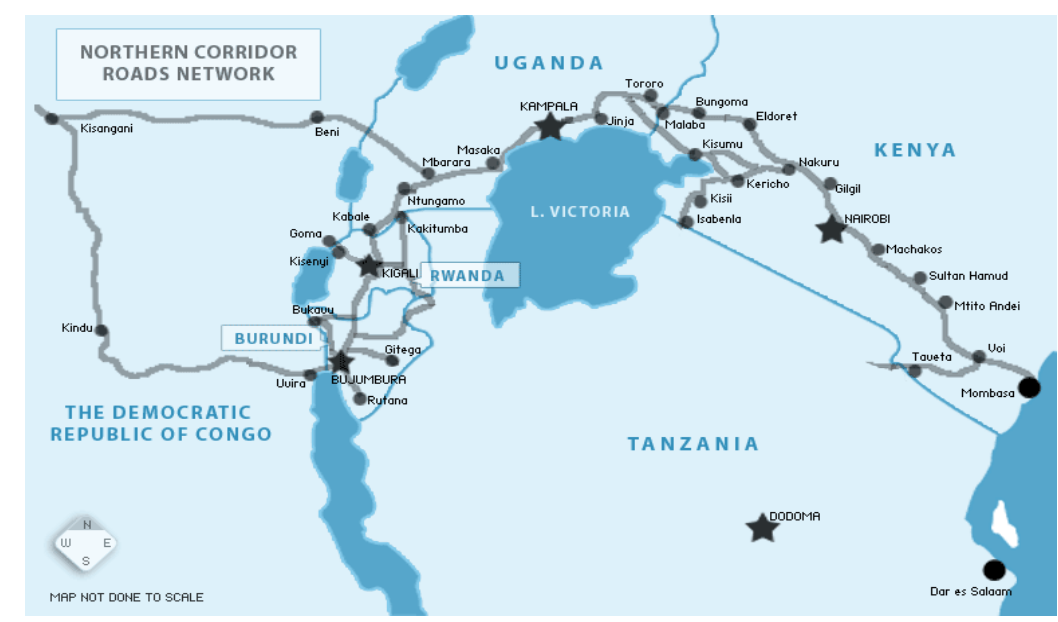

Figure 1. The East African Northern Corridor.

Source: Northern Corridor Transit Transport Facilitation Authority, http://www.ttcanc.org/maps.php 


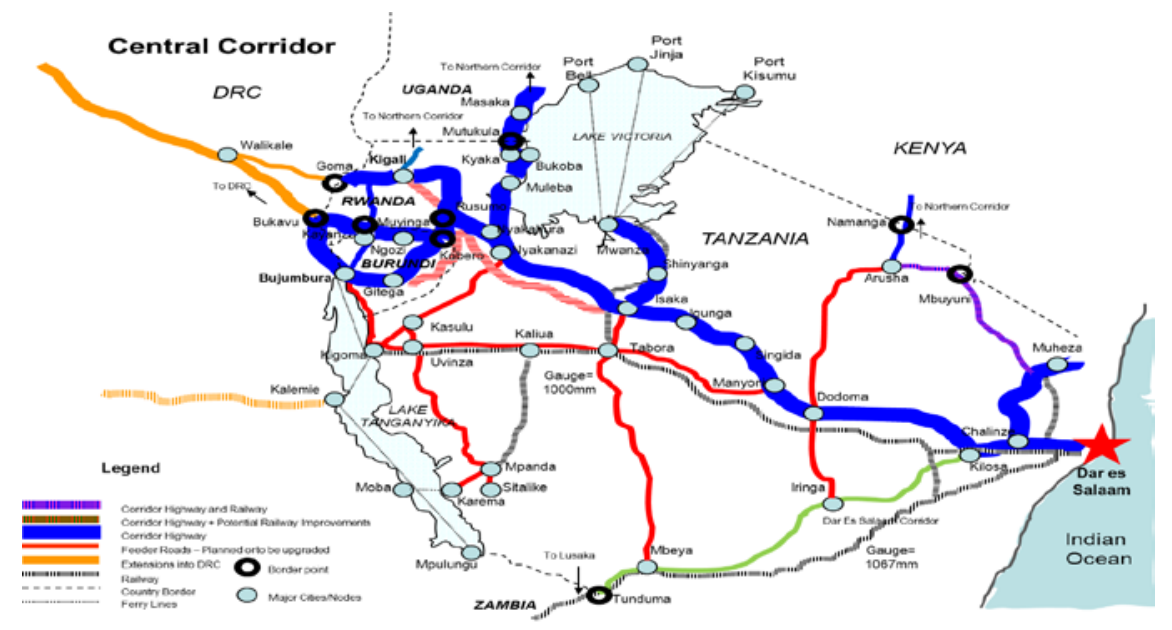

Figure 2. The East African Central Corridor.

Source: Central Corridor Transit Transport Facilitation Agency, http://centralcorridor-ttfa.org/about-us/central-corridor-trade-route/

2). It therefore commands a large regional cluster of countries, including Kenya, Uganda, Tanzania, Rwanda, Burundi, Southern Sudan and Eastern Congo; majority of which are land-locked (Gekara and Chhetri 2013).

The Northern Corridor is the main transport route in the East and Central African region, linking several countries, including Kenya, Uganda, Rwanda, Burundi, South Sudan and Eastern Democratic Republic of Congo. All these countries, aside from Kenya are landlocked and depend on the port of Mombasa as their primary maritime gateway. The development of the Lamu port, which is underway and also located on the Kenyan coast, will provide the second major gateway, primarily linking to South Sudan, Uganda and potentially Ethiopia.

The significance of the port can therefore not be overstated. Its regional significance is further enhanced by its link to the Central corridor at various transit points, including Mombasa through Lungalunga to Muheza, Nairobi to Arusha, through Namanga, and to Mwanza through lake Victoria (Figures 1 and 2). Although the port of Dar Es Salaam is the de facto key gateway to the Central Corridor, the port of Mombasa is a key alternative and ofttimes attracts trade meant for the Central Corridor due to perennial capacity challenges at the port of Dar Es Salaam (Gekara and Chhetri 2013). With this expansive hinterland the challenge that the port has faced, aside from historical logistics connectivity difficulties resulting from limited transport networks and poor transport infrastructure quality, which often lead to long dwell times, port congestion and slow port turn-around (Gekara and Chhetri 2013), is slow and inefficient communiction across customers and community stakeholders.

A single window cordination platform was needed to facilitate realtime and seamless exchange of information between carriers, shippers and the port so as to enhance overall efficiency and operations transparency. However for a single window strategy to be implemented successfully, the port required an advanced ICT-TOS. It is against this background that the port commenced its adoption and implementation of its ICT-TOS at the start of the $21^{\text {st }}$ Century. The choice, adoption and implementation will be further discussed after a brief outline of container termkinal operating systems and description of the study methods in sections three and four.

\subsection{Container Terminal Operating Systems (CTOS)}

Ports increasingly operate within a highly competitive and fast changing global shipping industry. With the advancement of container shipping technologies, the consolidation of shipping business into fewer dominant shipping companies, alongside increasingly bigger and faster ships carrying an ever-growing international trade volume, efficient and agile container terminals are ever more critical. Between the 1960s and 1980s, when containerisation became widely established as the dominant transportation mode in international trade, port technology underwent tremendous transformation, particularly in terms of advanced equipment for ship reception and cargo operations at container terminals. The main drive was the need for efficient cargo transfer and ship turn-around, and an overall efficient shipping industry. By the 1990s, most ports around the world had achieved remarkable levels of mechanisation, yet overall inefficiency in communication and document transmission within the terminal and between customers and key stakeholders remained a major bottleneck, undermining overall performance (Gekara 
and Thanh Nguyen 2018). It is against this context that ICT-CTO systems were developed, effectively from the mid-1980s (Gekara and Thanh Nguyen 2018; Kia et al. 2000). As Gekara and Thanh Nguyen (2018: 225) explain:

Computerisation of the management of cargo operations at container terminals was, therefore, a necessary response aimed at enhancing the capacity for, and accuracy in collecting, storing and processing large volumes of data, and transmitting critical information across a wide variety of cargo interests.

Whilst the original CTOS were basic in their design and application, and mostly used to support container operations related clerical work, they transformed, within a short space of time, into highly comprehensive systems providing sophisticated interactive electronic platforms for interaction between the wide range of terminal users and cargo interests (Choi et al. 2003; Gekara and Thanh Nguyen 2018). As a core function, they comprise a synchronised set of digitalised procedures that coordinate, plan and manage all aspects of the delivery, processing and movement of container cargo through the port and onwards to inland destination (Choi et al. 2003). Min et al. (2017) explain that CTOS often comprise various modules essential for cargo operations and stakeholder coordination, including berthing, vessel planning, resource planning, communication and yard planning modules. They define TOS as:

a computer system that is designed to plan, track, and manage the movement and storage of all cargo, the use of assets, and the deployment of people in and around the seaport terminal or the port (including the hinterland) on a real-time basis (Min et al. 2017: 431).

Over the last two decades, as pressure for enhanced operational efficiency increased, a wide variety of products have emerged. Some of the most popular ones include Navis SPARCS N4, Computer Automation Terminal Operating Systems (CATOS), Mainsail Vanguard, TOPS, OPUS, HD-CiTOS (Huadong Computer Intelligent Terminal Operation System) and Computer Integrated Terminal Operations System (CITOS) (see Kim and Lee 2015 for a detailed description of the different products available). While the literature mostly highlights the traditional drivers of efficiency such as location, sea and land access, maritime shipping services, dynamism of port authorities, and terminal organization and logistics integration (e.g., Felício et al. 2015), there is growing focus on the role of advanced ICT-CTOS in the enhancement of terminal performance and international competitiveness (e.g., Choi et al. 2003; Gekara and Thanh Nguyen 2018; Kia et al. 2000; Min et al. 2017). The CTOS adopted for the case port was CATOS, which we shall examine more closely in a later section, after a brief description of the study methods in the following section.

\section{Research methods}

This study was developed to examine the adoption and implementation of the ICT-TO system - CATOS - with a focus on the key motivations, the implementation process, the challenges and outcomes in the context of the African region. The port of Mombasa was used as the study port for two reasons. First, it is one of the major regional ports which, as explained previously, serves several land-locked countries in the East and Central African region. Second, it is one of the few ports in Africa which has recently pursued advanced innovation as it seeks to position itself for a more critical role as an important regional trade gateway for the MSR. The study comprised a qualitative single-case study methodology (Baxter and Jack 2008; Hellström and Nilsson 2011; Yin 2003) utilising semi-structured interviews, non-participant observations of container operations, informal conversations with terminal workers, supervisors and managers, recorded in the form of retrospective field notes as well as content analysis of relevant policy documents and reports provided by the port.

The data was collected in two focused fieldwork phases - November to January 2011 and August to September 2018 - with regular follow-up with key informants through emails and phone calls in the interceding period. This approach enabled a cumulative observation of the adoption and implementation process, beginning with understanding the motivations, choice of technologies and implementation plans, in the first phase, and then an assessment of the challenges, outcomes and implications after a reasonable ten-year period and the period between. Through follow-up correspondence with research contacts at the port during the interceding period, it became increasingly clear that the implementation had been marred by major challenges and largely failed. In one such correspondence in June 2015, an informant described the situation as “... a complete mess”, while another, in July 2018, was of the view that "... the only way to get back on track with this project is to do a total overhaul, a complete start from the beginning” because, as he added, “... it has all gone wrong” (Research field-notes). 
Considering that these systems are now widely available in standard products and widely and successfully implemented across many terminals, it became important to find out the breadth of factors hindering their implantation at the case port. A total of 24 formal interviews (15 in 2011 and 7 in 2018) were collected with officials in difference key sections of the organisation including, the human resource, information technology (IT), policy and strategy, operations and logistics departments. One interview was conducted with a long-term clearing agent associated with the port as well as an external ICT consultant with expertise in ICT-CTOS. The interviews lasted approximate 2 hours each totalling about 42 hours of interview recording. In addition, approximately ten hours of informal conversation took place during non-participant observations.

Having been formally transcribed, the data were analysed following Miles and Huberman's (1994) thematic analysis approach as well as Tornatzky and Fleisher's (1990) TOE framework. The data were dissected and extracts illustrating different factors and influences in the TOE were accordingly allocated and later critically examined to develop and illustrate the discussion in this paper. While interviews from the earlier phase of the study provide material for describing motivation, adoption and outcomes, including the nature and extent of failure, those from the latter phase are used to support a critical analysis and discussion of the reasons for the observed outcomes.

\subsection{ICT-CTOS adoption at the case port; the technology, motivations and outcomes}

The port commenced its modernisation through ICT in 2001 with the installation of the Internet and establishment of an official port website. Prior to that, all forms of communication, including document transmission and data capture, was via traditional methods, including snail mail, fax and physical hand deliveries by clerks and clearing agents. In 2002 the Systems Application and Products in Data Processing (SAP) was installed to automate the administrative and management functions of the port. This was followed by the implementation of the Electronic Data Interchange (EDI) platform in 2002, to facilitate more efficient and real-time exchange of essential data and information between the port, its users and other key stakeholders. The TOS product CATOS, developed by the Korean company Total Soft Bank (TSB), was launched in 2008. It comprises three broad suites, including CATOS Planning System, CATOS Management System and CATOS Operations System (Figure 3).

These three are designed in such a way that, when properly applied, they are sequentially integrated to seamlessly coordinate the total cargo process from terminal gate to ships rail and vice versa, while linking all key stakeholders into a common realtime information sharing platform. The planning system ensures that the schedules for ship arrival and berthing are efficiently coordinated and aligned with yard plans and the schedules of hinterland freight-forwarding operations. These schedules are in turn synchronized with the functions of the operating system, which allocates and manages resources, including yard equipment and personnel, and monitors the stacking and movement of containers in, around and out of the yard. The combined effect of these two systems is significant timesaving in cargo processing and onward transfer. At the interface of these two systems is the CATOS Management System, which is essentially a platform upon which information and document exchange, between the terminal and shippers, carriers, forwarders and other key stakeholders, such as customs agencies and revenue authorities,

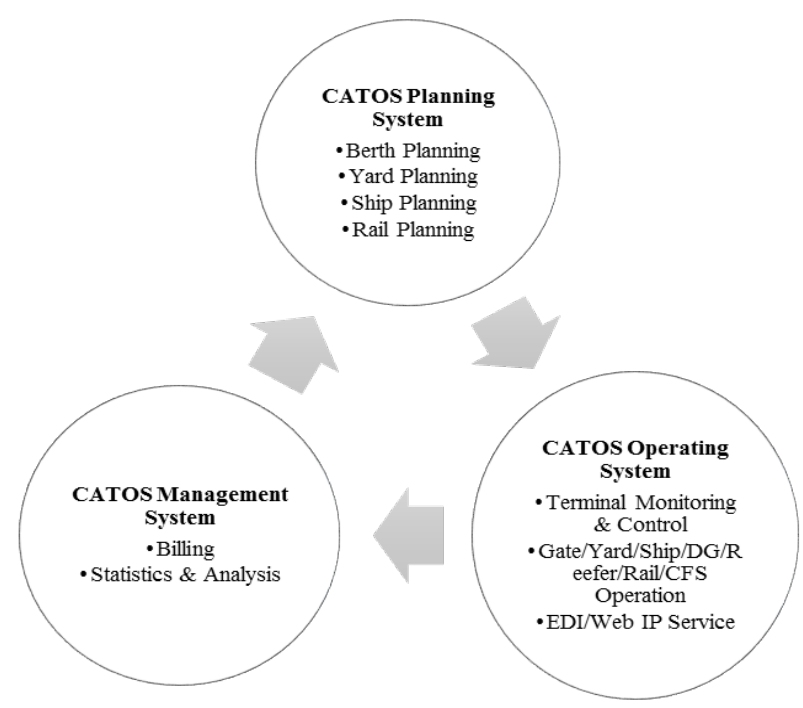

Figure 3. Outline of the CATOS system.

Source: Based on Total Soft Bank Ltd, http://www.tsb.co.kr/en/sub01_01_01.php. [1/3/2019] 
can be transmitted in real-time through EDI, e-mails, web etc. It also provides an integrated billing platform to enable timely and synchronized payment (see Kim and Lee 2015 for a more detailed technical description of the systems).

Discussions with port officials participating in this study, as well as review of official policy reports, reveal that the aggressive approach to adopting ICT at the port was driven by an urgent need to improve operations efficiency and assuage growing customer concerns in the 1990s, particularly about perennial cargo delays and associated overall cost. Not only were carriers frustrated with long ship delays, cargo owners were also increasingly frustrated with lengthy cargo dwell times. The port found itself faced with the growing threat of losing business to neighboring competitor ports. The aim, therefore, as per the principal port ICT policy document was to implement an effective ICT-CTO system that would facilitate efficiency, provide process visibility and restore user confidence. It was also, apparently important not to be left out of the global Belt and Road project, as explained by an operations manager at the terminal:

The One-Belt-One Road initiative is very important to us as a port and country ...we are the key gateway to the whole [East and Central Africa] region and if we do not increase out efficiency, we will lose our position and left behind... All that economic benefit will be lost (Senior terminal operations official 2018).

A big part of the inefficiency resulted from the large amount of paperwork and a lengthy manual cargo clearing processes, which involved navigating multiple clearing points within the expansive port complex. As explained by one participant, there were, at one stage, as many as forty-five points at which physical document inspection was done and clearance given in the form of an official clearance stamp. An interviewee captures the situation as follows:

There were so many stamps to the extent that you couldn't tell the writing on the original document because you needed up to 45 stamps ... An agent walked about 22 kilometres through all the up to 45 different clearing stations located in places ... Sometimes it took several days to complete clearing one single container (Terminal cargo clearing official 2018).

Closely associated with this lengthy manual clearing process was a lack of process transparency, visibility and traceability. As explained by various interviewees, documents could easily disappear, get misplaced, mysteriously hidden or withheld to facilitate financial extortion and fraudulent rent seeking by officials at the multiple clearing stations. These issues not only introduced large amounts of hidden costs to customers but also held up cargo operations, particularly in cases where clearing agents were unable, or unwilling, to pay bribes to clearing officials. A clearing agent familiar with the situation described is as follows:

You realize with the many stamps ... either you do something [pay a bribe] or the document disappears, or the stamp cannot be seen - so many reasons. Once you pay something then you can move on, and it happens at every point (Senior terminal operations official 2011).

Cross-agency coordination of cargo operation processes was also slow and highly problematic because of poor process visibility and interaction. Seemingly, with the introduction of the CTOS and supporting systems, many these issues have been addressed to some extent. An internally commissioned report into ICT implementation in the port concludes that the new systems have brought significant improvements in the efficiency of operations. These include significant reduction in the amount of paperwork, enhanced process transparency and reduced opportunity for official corruption, and an overall faster gate to rail cargo clearing process. All these apparently led to a significant rise in port revenue whereby the total revenue and profit before tax jumped by 33\% and 207\% respectively between 2008 and 2009, being the period immediately after implementing the system.

With the supposed gains, however, there are apparently fundamental issues. The same quoted report concludes that, "the [CTOS] system is severely underutilized and, in some instances, not properly applied...”. In similar vein one of the interviewees explained that after ten years of trying to implement the system and facing many challenges, the port was looking into either “... revamp the same or a total overhaul so that we install a new one" (Senior policy official 2018). Most of the interviews echo this observation; with some pointing out that the gains noted initially were beginning to wind back. At the heart of what was variously described as a 'total mess', was the problem of the system producing inaccurate and misleading data and reports, as captured in the following interview extract: 
... the system tells you the container is still at the port but in actual fact the container left a few months ago but, because someone somewhere did not enter the right code, the correct status is not entered... By the time we are reaching the crisis level we had 135,000 containers in the inventory of CATOS. When you look at the physical count of inventory in the yard, we had about 15,000 (CATOS management official 2018).

So how is this possible and what went wrong? The interviews reveal critical failures in the implementation process leading to the outcomes observed and reported here. Apparently, due to a myriad of reasons that will be discussed in the next section, the port ended up with two, constantly conflicting systems, running concurrently - the old manual system and the new ICTCTOS. They seemed to intersect at different points as users switched from one to the other in what appeared to be a highly chaotic environment. Using the TOE framework, the following section examines the combination of factors behind the situation.

\subsection{Technology implementation failure factors}

As many economies enter the fourth industrial revolution and the use of ICT becomes widespread both at the personal and firm levels, it is increasingly critical for adopters, implementers and users to develop sufficient understanding of the contexts and factors that facilitate or inhibit effective adoption and implementation. In this study we examine the same from the perspective of container terminal technology implementation. Following the Technological Organisational and Environmental framework to identify and discuss key factors, which influenced the outcomes. A summary of the key influences is contained in Table 1.

\subsubsection{Technological factors}

The analysis reveals that overall unpreparedness, with regard to the underlying IT infrastructure to support the new system, was a major factor in this case. As explained by an ICT-CTOS expert interviewed for the study, "you have to have the appropriate infrastructure for the new TOS adoption to succeed". A port official involved in the implementation of the system confirmed the situation as follows:

The system was installed on servers that were almost getting to the end of their factory lives and eventually they did, and the system was almost crashing because of that (Senior port IT official 2018).

The technology problem manifests in several ways. For example, in the form of out-dated hardware and software on which the new system was installed, and a weak and unstable broadband network which, according to an interviewee, was “...erratic...” and often failed "...forcing people to go back and forth to manual operations” (CATOS implementation official 2018a). Critically too, the system modules had not been upgraded since installation. As explained by another interviewee, the port “....is currently using [CATOS] version 7.1 whereas in the market it is up to version 7.7 and the developer is already developing 7.8” (Senior port IT official 2018).

Seemingly also there was a failure to effectively integrate the different system modules, for example the mainframe CATOS system, the separate EDI platform that was installed earlier in 2002 and the Integrated Security System (ISS) that was installed

Table 1. Key TOE factors influencing the adoption and implementation of TOS at the port

\begin{tabular}{|c|c|c|}
\hline Technological & Organisational & Environmental \\
\hline $\begin{array}{l}\text { - Failure to upgrade system modules } \\
\text { - Inadequate underlying IT infrastructure } \\
\text { - Installation on weak and obsolete servers } \\
\text { - Poor system module integration } \\
\text { - A weak and unstable internal broadband } \\
\text { network } \\
\text { - Lack of appropriate local technical know- } \\
\text { how } \\
\text { - System over-customisation }\end{array}$ & $\begin{array}{l}\text { - Weak workforce computer skills base } \\
\text { - Poor workforce planning and skills transfer } \\
\text { - Failure to maintain continuous skills update for } \\
\text { trained users } \\
\text { - Worker resistance to the new systems } \\
\text { - Poor work ethics and attitudes among workers } \\
\text { - Poor digital organisational digital culture } \\
\text { - Low middle-management buy-in and support } \\
\text { - Failure to allocate dedicated budget }\end{array}$ & $\begin{array}{l}\text { - Weak and unstable national broadband } \\
\text { system } \\
\text { - Extent of business ICT diffusion } \\
\text { - Poor customer and stakeholder digital } \\
\text { skills capacity } \\
\text { - A weak overall digital skills } \\
\text { environment }\end{array}$ \\
\hline
\end{tabular}

TOE, technological, organisational and environmental; TOS, terminal operating systems; IT, information technology; ICT, information communication technology. 
later in 2011. This presented critical problems relating to poor access and visibility across different user groups where “...the systems [did] not talk to each other properly” (CATOS implementation official 2018a). Another official explained that:

... operations people are supposed to clear containers out of the port, but it is someone from security who issues the final gate-pass but these two systems [CATOS and ISS] are not talking to each other... That is why you hear that a container left but we are not aware, or a container has been stolen (Senior terminal operations official 2018).

Seemingly too, the system had been over-customised with different additions and modifications, which severely affected its functioning. Apparently, piece-meal installation of the system and unsuccessful attempt to integrate separate modules developed and supplied by different vendors, presented major issues. As explained by the ICT-CTOS expert interviewed, IT system customisation is "...likely to go all awry when it is poorly done... Then you get situations where different parts do not talk to each other”. To compound the problem, the port lacked sufficient and appropriate technical skills to manage the installation and integration. As explained by one interviewee, the port was therefore “.. totally dependent on the system provider. Even minor issues, technical problems, we have to call or email S. Korea (Terminal ICT policy official 2018). The skills challenge appeared as one of the major obstacles to the installation and effective use of the CTO system and will be discussed in greater detail under the analysis of organisational factors next.

\subsubsection{Organisational factors}

Under the organisational factor category, 'human factor issues' were highlighted as the major problem underlying implementation failures. As one interviewee emphasised, “I can describe it as a people issue, it is not about the system, I don't think" (Senior terminal operations official). Interviewees variously described technical people issues, people issues related to workers' resistance to the new technologies, people issues related to workers' general work ethics and people issues related to management attitude towards supervision of the system.

Most of the technical people issues identified, however, referred to workforce skills and technical know-how. To begin with, there was a generally weak computer or digital skills base in the organisation and in the broader prevailing context, which meant that the knowledge and skills to operate effectively within the new system had to be developed almost entirely from within. Consequently, as already highlighted, there was over-dependence on the system developer to solve even minor technical and operational issues.

However, seemingly, it was not a case of total failure to train the implementers and users within the port. Apparently, as pointed out by one interviewee, there was a huge initial training drive involving selected staff from across different sections considered essential for the system's implementation. These were referred to as the 'super users.'

There was a lot of training, initially... They even sent people to overseas; India South Africa, South Korea... what you would call super users - the ones who would now have the knowledge to train the rest - these are the ones who were sent to these places for training (CATOS implementation official 2018b).

However, there seems to have been no attempt at sustaining the training and skilling effort as, apparently, a short while into the implementation the training ceased, both for new and continuing users. There also seems to have been no systematic and sustainable approach to developing and allocating the workforce. Because of a system of promotion based on acquisition of additional credentials, many of the initial group of super users were promoted and mostly transferred to other departments and reassigned different roles - many unrelated to the immediate operation of the system for which they were trained. Others were poached by other organisations because of their newly acquired valuable skills and the prevailing shortage of digital skills in the general labour market, which meant that digitally skilled workers were highly sought after, and interviewees gave examples of people within the original super users who had moved to other companies soon after acquiring the training.

Because by this time the initial training efforts had ceased, the port's pool of CATOS trained and skilled workers was quickly depleted. People who were recruited to run the system later might have had some general digital training but lacked the specific skills required to run CATOS and were provided little, if any, training as described by one such employee who said that since joining the organisation, a few years previously into a key role within the new system, she had not received any training. Instead emphasising that, "everything I know, I have known through just getting in and getting my hands dirty (CATOS implementation official 2018b). The following quote from another interviewee best illustrates these problems and the associated impact: 
What happed is that there was a team that was set up initially called super users, but the super users have since been transferred to different areas and levels of the organization and they were transferred with the knowledge without being replaced with equally trained people (CATOS management official 2018).

It is therefore a compounded problem of failure to provide adequate training and continuous replenishment of user skills, as well as poor workforce planning, which according to one of the CATOS implementation official (b), “...left the system vulnerable".

The skills problem is, however, much more pervasive. Lack of basic computer skills among the general workforce, led to system failure on many occasions, as people misused equipment such as hand-held terminals (HHT) and vehicle mounted terminals (VMT) - touch screen data entry and clearance devices. In other situations, workers at different stations often ignored to use the system devices “...because they found them difficult or unfamiliar...” (CATOS implementation official 2018a). In such cases they reverted to paper-based clearance leading to the chaos and confusion described in the previous section. Apparently, this confusion and clash between the manual and automated processes was also influenced because external users such as cargo clearance agents and freight forwarders, who were supposed to use the system to lodge documentation, failed to do so; instead presenting them in hard copy. The port was therefore not only struggling with a skills problem within but had to contend with the fact that external essential users were unable to effectively use the system.

Another major people problem was a general resistance to, and unfriendly reception of, the new technologies by the general workforce. This seems to have resulted from a fear of potential employment and/or income loss with the increasing digitalisation of work. The new technologies were therefore met with suspicion which led opposition and resistance to what was viewed as management's attempt to replace workers with technology. Workers in strategic cargo clearance roles and who worked directly with the technology engaged in various forms of passive and active resistance, including deliberately avoiding use of the system and/or covertly vandalising and destroying the systems electronic devices such as HHTs and VMTs, as illustrated in the quote below:

... so, they started peeling off the VMTs... So now they would, for example, plug out the critical keys... like where you key in to confirm, so now how do you confirm. You are left with a stylus, which gets lost as well. When we started gluing in the keys then they now started kind of bending the pins that connect the keyboard to the monitor. So those pins now they would kind of cut them or bend them so you cannot plug it is and therefore the keyboard cannot work (Senior terminal operations official 2018).

The so-called people issue clearly played a big part in the failure of the implementation of the container terminal operating system in the case port. It came out as the most significant of all possible organisational factors, perhaps pointing to an important area that management must pay attention to in similar technology implementation projects. The general environment within which the port was attempting to innovate was also critical in the outcomes observed, as discussed next.

\subsubsection{Environmental factors}

Quantitatively, it might appear that environmental factors were less influential, based on the number of elements highlighted in the interviews (Table 1). Yet it is the environment within which organisations attempt to innovate that, ultimately, determines outcomes. Recent research has highlighted the importance of environmental factors on technology adoption, particularly in developing economies (e.g., Ejiaku 2014; Gekara and Chhetri 2013; Richardson 2011). For example, an important environmental factor underlying the technological impediments discussed earlier is the state of the national broadband network. Interviewees underscored the challenges associated with weak and often unstable Internet connectivity, which often failed, forcing constant switch between electronic and manual systems.

... we also do not have a stable network connectivity to support our systems. We actually at times have what we call erratic system downtime... and when the system goes down we immediately resort to manual ... (Port ICT policy official 2018).

Furthermore, even if the port's Internet was stable, there was no guarantee that the same was true at the wide range of organisations and agencies whose systems needed to constantly interact with the port's electronic TOS. This was because, although the port was well serviced by the national fibre optic broadband network, many other businesses, were not, which 
meant that the port's TOS could not effectively perform as intended, i.e., to electronically facilitate the interaction of different port users in one seamless operation. As summed up by one interviewee:

... the interface with the other stakeholders, most of them do not have systems which can link with our systems (Senior terminal operations official 2018).

Because of the nature of the port's business, the success of its ICT-CTO system critically depended on its ability to interact, and effectively communicate, with systems at similarly ICT-enabled customer and partner organisations. This was, however, problematic in many instances as many stakeholders and users, including a large majority of the clearing and forwarding agencies, lacked similar, or even basic, level ICT infrastructure and systems. The general business environment lacked essential infrastructure to support the innovations that the port was undertaking. In their study, Chang et al. (2008) highlight the need for fit between business and the IT environment, noting that lack of fit produced extra burdens and cost in the buyer-supplier relationship.

A good illustration of the environmental issue in this case is the skills issue. As explained previously, the lack of digital skills in the general national environment meant that the port struggled to recruit appropriately skilled workers from the open labour market. Furthermore, when it trained its own workers, they because highly valuable in the marketplace and were targets of poaching by other organisations in the same position of attempting to innovate.

\section{Discussion of findings}

The MSR, and the ability for participating regions to effectively connect to it through critical infrastructure, is important. It is for this reason that many countries have increased expenditure in developing and upgrading infrastructure, including linking corridors and gateway ports. To this end, and in the African continent alone there are many port upgrade projects underway with the aim of integrating effectively into the global supply chain superhighways of which the MSR is becoming critical. The high number of ports and terminals around the continent that China's is directly or indirectly involved in their development (Chimbelu 2019) is an important indication of the significant of these facilities to the MRS's overall strategy.

An important issue however is whether the upgrade of these facilities, especially with new technologies, is successful and to what extent. Research has shown that a wide range of enablers and/or impediments often determine the outcome of technology adoption and implementation (Chang et al. 2008; Datta 2011; Pradhan et al. 2014; Shih et al. 2008). Some of this research shows that many technology transformation projects around the world, but especially in developing countries either fully or partially fail (Heeks 2002). This case study presents a good exemplar of how a wide range of factors, typical to developing economy contexts, combined to undermine desired outcomes and, ultimately, undermine the port's capacity to competitively integrate into the MSR. Although, in studies following TOE and like frameworks, some of the factors are viewed as being internal and more in the control of the firm, the actual situation is often very different. In the current case, the dominant obstacle was skills and worker's, as well as middle-management buy-in. Whereas these are generally categorised as organisational challenges which the organisation should be able to address through strategic allocation of resources to staff development, the particular context undermines even such efforts.

The lack of adequate digital skills in the general labour market means a shortage of skilled people to recruit but also, as pointed out earlier, that any training efforts by the organisation are undermined by poaching practices characteristic of such labour market situations, with a general shortage in the required skills. Furthermore, where the systems being adopted link to essential external operations, their success depends on external partner organisations having equally skilled workers. In this, as illustrated, external uses such as cargo clearing agents and freight forwarders lacked the essential skills and often opted to bypass the system and instead operate manually.

Technological hindrances were also highly influential, particularly the overall strength and stability of the national broadband network. In such situations, what is required is a strong and strategic national policy framework to support businesses in their attempts to innovate and enhance efficiencies and productivity. According to recent research, failure to properly prioritise action prevents any long-term solutions for the technology implementation failure in developing countries (Heeks 2002). Many governments have increased their investment in technologies, such as Internet infrastructure, and increasingly encourage and subsidise companies to adopt new advanced technologies. Nevertheless, there were significant internal failures in this case which significantly contributed to the outcomes. Significantly, the failure to develop and a coherent and sustainable skills and workforce development strategy is notable. The training offered at the initial stages only targeted key implementation managers 
and not general users, thus did not address the core problem of lack of appropriate skills among primary system users. Also important is that the effort was not sustained, possibly because it was not based on an adequately long-term workforce development strategy. Furthermore, the workers were not adequately prepared to accept the technology, leading to the kind of resistance and hostility observed and what Sanchez (1996: 137) refers to as "unfavourable attitudes by [...] workers" in his study where he concludes that for successful technology implementation it is essential that:

[...] top management informs those affected of the firm's plans and motivations for automation-before the fact and even involves workers in the project to assure their cooperation and to overcome resistance to change.

He further observes that "several supports necessary to the successful implementation of new technologies", including the training of users "reduces resistance to change and makes workers better prepared to solve problems that arise, thereby reducing dependence on hardware and software suppliers" (138). A slightly different but additional view is presented by Azzee (1982) who, in his study of the technology transfer in shipping, argues that organisations must effectively transfer technology into the 'hearts, minds and hands' of the people to make implementation work. However, in his view, lack of incentive to make the necessary efforts is an often-major obstacle which management must overcome. Conventional ways of education and training, on their own, are not enough to bring about the necessary, comprehensive institutional cultural shift to accommodate technological change.

\section{Conclusions}

This paper presented a qualitative case study-based analysis of the adoption and implementation of an ICT-driven terminal operating system at the port of Mombasa. It identifies and discusses some of the key motivations for the adoption of the new technologies and the challenges experienced in the process of implementation. The port of Mombasa is the key gateway to an expansive economic hinterland covering the whole of East and Central Africa. This means that in its ordinary operations, it coordinates a wide variety of customers and stakeholders across the different origin and destinations countries. These include cargo owners, carriers, freight forwarders and customs agencies. The complexity of such coordination and the critical importance of real-time and seamless information exchange across these parties necessitated the adoption and installation of a sophisticated ICT terminal operating system, which would support, a multi-user, comprehensive single-window operating system, as well as efficient internal operations. It is also important to consider the ports key and strategic role within the increasingly important MSR project. Failure to attain and maintain international standards of efficient operations and effective integration with other ports and logistics stakeholders along the MSR is likely to jeopardise the ports position as the key regional port. An advanced ICT-TOS is widely seen as a critical efficiency boost and step towards terminal automation (Kia et al. 2000).

The implementation of the selected TOS - CATOS - was, however, problematic and replete with challenges, to the extent that, by the time of the final phase of the study in 2018, it was deemed largely unsuccessful and requiring a complete overhaul. In view of the foregoing analysis, we conclude that due to the complex interplay of a wide variety of failure factors involved, an equally multi-pronged, comprehemsive and integrated approach is required, involving government, industry and labour. The core, generic and underlying issues must be identified and strategies appropriately prioritised in order to create an environent that effectively supports technology adoption and implementation. However, we also recognise that our study is highly limited in scope and recommend a more comoprehensive study involving a wider selction of ports in Africa in order to more exhaustively examine the context of technology implementation and develop stronger theoretical understanding of why these are likely to fail and what measures must be taken to avoid such outcomes.

\section{References}

Azzee, B. B. H., 1982. Shipping and the transfer of technology. Maritime Policy \& Management 9, 229-234.

Baxter, P., Jack, S., 2008. Qualitative case study methodology: Study design and implementation for novice researchers. The Qualitative Report 13, 544-559.

Chang, H. L., Wang, K., Chiu, I., 2008. Business-IT fit in e-procurement systems: Evidence from high-technology firms in China. Information Systems Journal 18, 381-404.

Cheng, L. K., 2016. Three questions on china’s “Belt and Road Initiative”. China Economic Review 40, 309-313.

Chimbelu, C., 2019. Making Chinese investment in African ports work despite risks. Available at: https://www. 
dw.com/en/making-chinese-investment-in-african-ports-work-despite-risks/a-49282176

Choi, H. R., Kim, H. S., Park, B. J., Park, N. K., Lee, S. W., 2003. An ERP approach for container terminal operating systems. Maritime Policy \& Management 30, 197-210.

Datta, P., 2011. A preliminary study of ecommerce adoption in developing countries. Information Systems Journal 21, 3-32.

Du, M. M., 2016. China’s “One Belt, One Road” initiative: Context, focus, institutions, and implications. The Chinese Journal of Global Governance 2, 30-43.

Ejiaku, S. A., 2014. Technology adoption: Issues and challenges in information technology adoption in emerging economies. Journal of International Technology and Information Management 23, 59-68.

Felício, J. A., Caldeirinha, V., Dionísio, A., 2015. The effect of port and container terminal characteristics on terminal performance. Maritime Economics \& Logistics 17, 493-514.

Gekara, V. O., Chhetri, P., 2013. Upstream transport corridor inefficiencies and the implications for port performance: A case analysis of Mombasa Port and the Northern Corridor. Maritime Policy \& Management 40, 559-573.

Gekara, V. O., Thanh Nguyen, V. X., 2018. New technologies and the transformation of work and skills: A study of computerisation and automation of Australian container terminals. New Technology, Work and Employment 33, 219233.

Georgiev, G. T., 2015. The Chinese “One Belt, One Road” Initiative - New opportunities for the European Union and its neighbors in the Black Sea region. KSI Transactions on Knowledge Society 8, 33-40.

Heeks, R., 2002. Information systems and developing countries: Failure, success, and local improvisations. The Information Society $18,101-112$.

Hellström, D., Nilsson, F., 2011. Logistics-driven packaging innovation: A case study at IKEA. International Journal of Retail \& Distribution Management 39, 638-657.

Kia, M., Shayan, E., Ghotb, F., 2000. The importance of information technology in port terminal operations. International Journal of Physical Distribution \& Logistics Management 30, 331-344.

Kim, K. H., Lee, H., 2015. Container terminal operation: Current trends and future challenges, In: Lee, C. Y., Meng, Q. (Eds), Handbook of Ocean Container Transport Logistics. Springer, Cham, Germany.

Lawrence, J. E., Tar, U. A., 2010. Barriers to e-commerce in developing countries. Information, Society and Justice 3, 23-35.

Lee, P. T. W., Hu, Z. H., Lee, S. J., Choi, K. S., Shin, S. H., 2018a. Research trends and agenda on the belt and road (B\&R) initiative with a focus on maritime transport. Maritime Policy \& Management 45, 282-300.

Lee, P. T. W., Lam, J. S. L., Lin, C. W., Hu, K. C., Cheong, I., 2018b. Developing the fifth generation port concept model: An empirical test. The International Journal of Logistics Management 29, 1098-1120.

Miles, M. B., Huberman, A. M., 1994. Qualitative Data Analysis: An Expanded Source Book. Sage, Thousand Oaks, CA.

Min, H., Ahn, S. B., Lee, H. S., Park, H., 2017. An integrated terminal operating system for enhancing the efficiency of seaport terminal operators. Maritime Economics \& Logistics 19, 428-450.

Pradhan, R. P., Arvin, M. B., Bahmani, S., Norman, N. R., 2014. Telecommunications infrastructure and economic growth: Comparative policy analysis for the G-20 developed and developing countries. Journal of Comparative Policy Analysis: Research and Practice 16, 401-423.

Richardson, J. W., 2011. Challenges of adopting the use of technology in less developed countries: The case of Cambodia. Comparative Education Review 55, 8-29.

Sanchez, A. M., 1996. Adopting advanced manufacturing technologies: Experience from Spain. Journal of Manufacturing Systems 15, 133-140.

Shih, E., Kraemer, K. L., Dedrick, J., 2008. IT diffusion in developing countries. Communications of the ACM 51, $43-48$.

Tornatzky, L. G., Fleischer, M., Chakrabarti, A. K., 1990. The Processes of Technological Innovation. Lexington Books, Lexington, Massachusetts.

Yin, R. K., 2003. Case Study Research: Design and Methods. Sage, Thousand Oaks, CA. 